\title{
Article
}

\section{Fly-Ash-Based Geopolymers Reinforced by Melamine Fibers}

\author{
Barbara Kozub (D), Patrycja Bazan (D), Dariusz Mierzwiński (D) and Kinga Korniejenko *(D) \\ Institute of Materials Engineering, Faculty of Material Engineering and Physics, Cracow University of \\ Technology, Jana Pawła II 37, 31-864 Cracow, Poland; barbara.kozub@pk.edu.pl (B.K.); \\ patrycja.bazan@pk.edu.pl (P.B.); dariusz.mierzwinski@pk.edu.pl (D.M.) \\ * Correspondence: kkorniejenko@pk.edu.pl
}

Citation: Kozub, B.; Bazan, P.;

Mierzwiński, D.; Korniejenko, K. Fly-Ash-Based Geopolymers Reinforced by Melamine Fibers. Materials 2021, 14, 400. http:// doi.org/10.3390/ma14020400

Received: 31 December 2020 Accepted: 12 January 2021 Published: 15 January 2021

Publisher's Note: MDPI stays neutral with regard to jurisdictional clai$\mathrm{ms}$ in published maps and institutional affiliations.

Copyright: $@ 2021$ by the authors. Licensee MDPI, Basel, Switzerland. This article is an open access article distributed under the terms and conditions of the Creative Commons Attribution (CC BY) license (https:// creativecommons.org/licenses/by/ $4.0 /)$.

\begin{abstract}
This paper presents the results of research on geopolymer composites based on fly ash with the addition of melamine fibers in amounts of $0.5 \%, 1 \%$ and $2 \%$ by weight and, for comparison, without the addition of fibers. The melamine fibers used in the tests retain their melamine resin properties by $100 \%$ and are characterized by excellent acoustic and thermal insulation as well as excellent filtration. In addition, these fibers are nonflammable, resistant to chemicals, resistant to UV radiation, characterized by high temperature resistance and, most importantly, do not show thermalrelated shrinking, melting and dripping. This paper presents the results of density measurements, compressive and flexural strength as well as the results of the measurement of thermal radiation changes in samples subjected to a temperature of $600{ }^{\circ} \mathrm{C}$. The results indicate that melamine fibers can be used as geopolymer reinforcement. The best result was achieved for $0.5 \%$ by weight amount of reinforcement, approximately $53 \mathrm{MPa}$, compared to $41 \mathrm{MPa}$ for a pure matrix. In the case of flexural strength, the best results were obtained for the samples made of unreinforced geopolymer and samples with the addition of $0.5 \%$ by weight of melamine fibers, which were characterized by bending strength values above $9 \mathrm{MPa}$, amounting to $10.7 \mathrm{MPa}$ and $9.3 \mathrm{MPa}$, respectively. The thermal radiation measurements and fire-jet test did not confirm the increasing thermal and fire resistance of the composites reinforced by melamine fiber.
\end{abstract}

Keywords: geopolymer composite; fly ash; melamine; compressive strength; flexural strength; thermal radiation changes

\section{Introduction}

Almost three decades ago, the French scientist Joseph Davidovits introduced the term "geopolymers" for aluminosilicate polymers formed in an alkaline environment [1-3]. Most geopolymer synthesis methods come down to one process, in which comminuted dried pozzolanic material (such as metakaolin [4-6], fly ash [7-10] or blast furnace slag [11,12]) is mixed with an aqueous solution of a suitable silicate (e.g., sodium or potassium silicate) with the addition of a strong base, usually concentrated sodium or potassium hydroxide. The resulting paste behaves similarly to the cement paste. It solidifies to a hard mass within a few hours; however, it is made without the use of Portland cement [13-15].

Geopolymers, due to their unique properties, have aroused the interests of not only scientific communities but also entrepreneurs interested in new competitive technologies over the past several years. Geopolymer-based products are increasingly beginning to appear on the market. In recent years, geopolymers have been considered some of the most interesting and promising building materials $[16,17]$. There are many types of geopolymers, and they have interesting applications. One of the most promising ways geopolymers are implemented is in fireproof and fire-resistant products such as shields able to withstand very high temperatures [18-20]. Numerous studies in the literature mainly present geopolymers as alternatives to cement for structural applications. Recently, several publications have appeared indicating their potential as thermal barriers [16,17]. These studies indicate that geopolymers can achieve high thermal stability and fire resistance. Moreover, the pro- 
duction technology itself can be classified as economical and safe, both for people and the environment. This presents a significant advantage over conventional thermal insulation materials, the properties of which, at a temperature of around $80{ }^{\circ} \mathrm{C}$, are significantly deteriorated; what is worse, they often emit dangerous emissions and toxic gases, posing a threat to human health and life [19-21].

A limitation to the wide application of geopolymer materials is their relatively low brittle behavior (crack resistance) [22,23]. Currently, one of the most important research areas concerns the improvement of these mechanical properties [24,25]. A well-known solution is the production of fiber-reinforced composite materials. Therefore, numerous studies have recently been conducted on the reinforcement possibilities of geopolymer materials with various types of fibers $[20,26]$. These studies mainly focus on the use of short fibers for the reinforcement of composites with a geopolymer matrix.

Polymer fibers are the most frequently used group of fibers as reinforcing additives [25]. The main objective of the addition of these types of fibers is improving mechanical properties, in particular bending strength $[24,27]$, and reducing the propagation of microcracks in materials $[23,28]$. Other benefits that can be achieved as a result of introducing chemical fibers into geopolymers, depending on their type, may include an increase in fire resistance $[24,27]$ or a decrease in the thermal conductivity coefficient. The main advantages of chemical, polymer fibers are their higher strength properties and repeatability compared to natural fibers [25,29]. Additional features desirable for particular applications may include decreasing the weight of geopolymer composites with the addition of polymer fibers $[24,25]$.

The background for this work was literature research showing the novelty aspects of the planned research. The available literature does not present research using as many possible fillers as reinforcement for geopolymer matrices, such as melamine fibers [25,29]. Research using melamine has been conducted with organic polymers. The results suggest that this kind of reinforcement could provide the composites with better thermal and fire resistance than using other polymer fibers, including glass fibers [30-32].

The present work attempts to design and test a new composite with better mechanical properties and increased thermal resistance compared to pure matrices $[33,34]$. This type of composite could be used as thermal insulation in civil engineering structures. This paper presents the results of research on geopolymer composites with a matrix based on fly ash and with the addition of melamine fibers in the amount of $0.5 \%, 1 \%$ and $2 \%$ by weight. The effect of melamine addition on selected properties of fly ash matrix geopolymers is then examined.

\section{Materials and Methods}

\subsection{Materials and Preparation of Samples}

The geopolymer matrix was made of F class fly ash from the Skawina Combined Heat and Power Plant (Skawina, Poland) and fine-grained, saturated-surface, dry construction sand (the surfaces of the sand particles are "dry" but the voids between the particles are saturated with water and there is no surface absorption) in the ratio 1:1. The type of fly ash used in this research consists mainly of silica and aluminum oxide and contains less than $4 \%$ calcium oxide. The exact percentage of the individual phases in the fly ash used can be found in Table 1 [29]. This type of fly ash is characterized by specific physical and chemical properties to support the process of geopolymerization $[35,36]$. 
Table 1. Identified phases with their percentage share: XRD analysis results [29].

\begin{tabular}{cccc}
\hline \multirow{2}{*}{ Precursor } & \multicolumn{2}{c}{ Identified Phase } & \multirow{2}{*}{ Percentages Content (\%) } \\
\cline { 2 - 3 } & Name & Chemical Formula & \\
\hline \multirow{4}{*}{ Fly ash } & Quartz & $\mathrm{SiO}_{2}$ & 42.3 \\
& Mullite & $\mathrm{Al}_{6} \mathrm{Si}_{2} \mathrm{O}_{13}$ & 54.8 \\
& Hematite & $\mathrm{Fe}_{2} \mathrm{O}_{3}$ & 0.6 \\
& Magnetite & $\mathrm{Fe}_{3} \mathrm{O}_{4}$ & 0.5 \\
& Anhydrite & $\mathrm{CaSO}_{4}$ & 1.4 \\
& Rutile & $\mathrm{TiO}_{2}$ & 0.4 \\
\hline
\end{tabular}

Melamine fibers (smartMELAMINE ${ }^{\circledR \circledast}$, the smart polymer GmbH, Rudolstadt, Germany) were used as reinforcement for the geopolymer composites. Melamine was added in an amount of $0.5 \%$ (sample marked as $0.5 \% \mathrm{MF}), 1 \%(1 \% \mathrm{MF})$ or $2 \%(2 \% \mathrm{MF})$ by weight of dry components (Table 2). A reference sample based on the matrix material without any additives (samples marked as $0 \% \mathrm{MF}$ ) was made for comparison.

Table 2. Designation of the manufactured composites.

\begin{tabular}{ccccc}
\hline \multirow{2}{*}{ Designation } & \multicolumn{2}{c}{ Mixture Proportion (\% by Weight) } & \multirow{2}{*}{ NaOH Solution } \\
\cline { 2 - 4 } & Fly Ash & Sand & Melamine Fiber & \\
\hline $0 \% \mathrm{MF}$ & 50 & 50 & - & 10 M sodium hydroxide \\
$0.5 \% \mathrm{MF}$ & 49.75 & 49.75 & 0.5 & solution + water glass \\
1\%MF & 49.5 & 49.5 & 1.0 & (1200 mL in total) \\
$2 \% \mathrm{MF}$ & 49.0 & 49.0 & 2.0 & \\
\hline
\end{tabular}

In this study, a nonwoven fabric (consisting of very fine melamine fibers), with a texture resembling wadding was used, cut into pieces about $5 \mathrm{~mm}$ long (Figure 1). The melamine fibers used in the tests retain their melamine resin properties and are characterized by excellent acoustic and thermal insulation as well as excellent filtration. In addition, these fibers are nonflammable, resistant to chemicals, resistant to UV (ultraviolet) radiation, characterized by high temperature resistance and, most importantly, they do not show thermalrelated shrinking, melting and dripping [37].

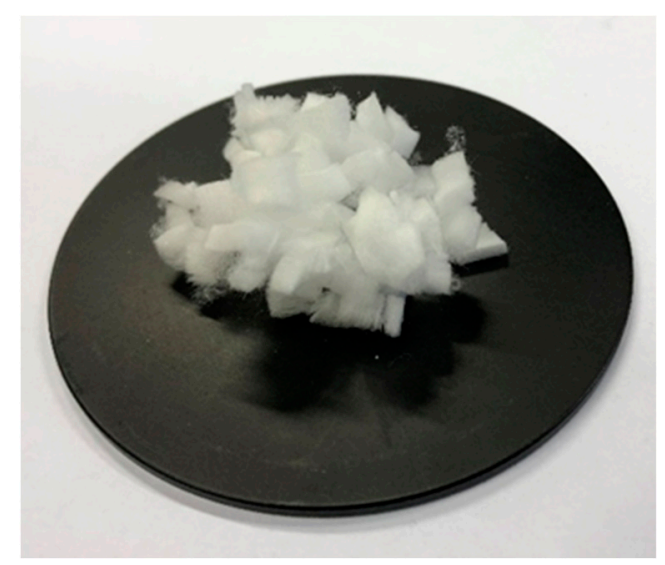

Figure 1. Melamine fibers.

As an alkaline activator, a 10-molar (10 M) sodium hydroxide solution and a sodium water glass R-145 (with a molar module of 2.5 and a density of about $1.45 \mathrm{~g} / \mathrm{cm}^{3}$ ) combined in the ratio of 1:2 were used. The alkaline solution was prepared by pouring an aqueous solution of sodium silicate into the flakes of the technical sodium hydroxide dissolved in water. The solution was then mixed thoroughly and allowed to equilibrate until a constant concentration and ambient temperature were reached, which took nearly $2 \mathrm{~h}$. The W/C 
ratio was selected according to a previous experiment [29]. To prepare geopolymer masses, the fly ash, construction sand, melamine fibers and alkaline solution were mixed to achieve a homogeneous paste for about $20 \mathrm{~min}$ in a low-speed mixing machine. The solid ingredients were added to fire and followed by liquid. The melamine fibers were dispersed randomly in the geopolymer matrix, and the homogeneous dispersion of the fibers was assessed visually.

In the next step, the prepared masses were poured into plastic molds, which were subjected to vibration on a vibrating table in order to remove air bubbles. The tightly closed molds were then heated at a temperature of $75{ }^{\circ} \mathrm{C}$ in a laboratory dryer for $24 \mathrm{~h}$. After 28 days, the samples were unmolded, tested and stored in laboratory conditions (temperature ca. $20^{\circ} \mathrm{C}$, relative humidity ca. $50 \%$ ).

\subsection{Methodology}

\subsubsection{Density}

Before carrying out the strength tests, the density of the samples was determined using the geometric method. The density for each of the analyzed geopolymer compositions was determined as the average of the measurements for four samples. The dimensions of the samples were measured with a laboratory caliper with a measuring accuracy of $0.01 \mathrm{~mm}$, and the weight of the samples was determined using the RADWAG PS 200/2000.R2 laboratory precise analytical balance (maximum load: 200/2000 g; reading accuracy: 0.001/0.01 g). Because the composites were not characterized by significant porosity (solid material without voids), the calculations were carried out for solid, nonporous materials.

\subsubsection{Strength Tests}

Due to the lack of separate standards for geopolymer materials, the compressive strength tests were carried out in accordance with the procedure described in the standard for concrete, EN 12390-3 ("Testing hardened concrete. Compressive strength of test specimens"). The tests were carried out on the Matest $3000 \mathrm{kN}$ (Matest, Treviolo, Italy) universal strength testing machine with a speed of $0.05 \mathrm{MPa} / \mathrm{s}$. For each analyzed chemical composition of geopolymer composites, four cubic samples with dimensions (approximately) $50 \mathrm{~mm} \times 50 \mathrm{~mm} \times 50 \mathrm{~mm}$ were made and tested for each composition. The dimensions of the samples comply with the EN 12390-3 standard.

Flexural strength tests were also performed. As in the case of the compressive strength tests, due to the lack of standards for geopolymers, the standard for concrete EN 12390-5 ("Testing hardened concrete. Flexural strength of test specimens") was used. The tests were also carried out on the Matest $3000 \mathrm{kN}$ universal testing machine with a speed of $0.05 \mathrm{MPa} / \mathrm{s}$. For each analyzed geopolymer composites, four prismatic samples with dimensions (approximately) of $50 \mathrm{~mm} \times 50 \mathrm{~mm} \times 200 \mathrm{~mm}$ were made and tested for each composition, with the distance between the support points equal to $150 \mathrm{~mm}$. The dimensions of the samples comply with the EN 12390-5 standard.

\subsubsection{Thermal Radiation}

Four plates were subjected to thermal radiation measurement. Each sample, in the form of a plate with dimensions (approximately) $50 \mathrm{~mm} \times 100 \mathrm{~mm} \times 150 \mathrm{~mm}$, was placed in a silicate chamber (electric) furnace in such a way as to constitute an insulating element, according to the scheme presented in Figure 2. The sealing element between the sample and the walls of the furnace was an element made of an insulating material able to withstand temperatures up to about $1500{ }^{\circ} \mathrm{C}$. 


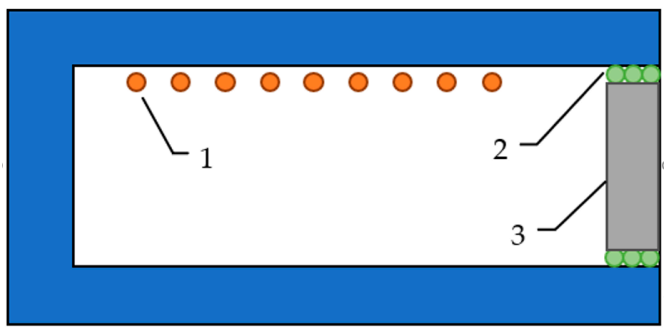

Figure 2. Scheme of the measuring system showing thermal radiation: (1) heating element; (2) hightemperature insulation material; (3) sample.

The measurement of the change in thermal radiation was performed on the surface of the sample constituting the external part of the measuring system (Figure 3).

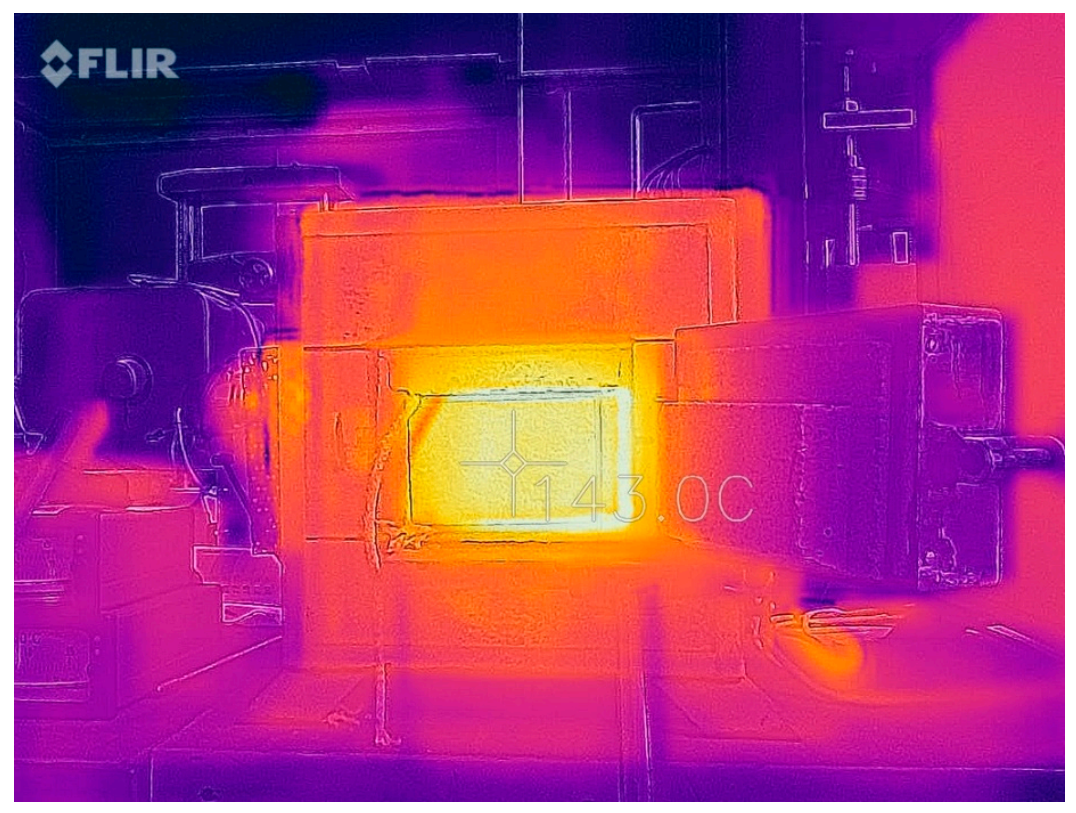

Figure 3. Sample photo of the measurement of thermal radiation.

The measurement was performed with a FLIR thermal imaging camera with a field of view $(\mathrm{FOV}) \geq 38^{\circ}$, thermal sensitivity $<70 \mathrm{mK}$, measured infrared wavelength range in the range of $7-14 \mu \mathrm{m}$ and pixel size $<15 \mu \mathrm{m}$. The thermal camera was placed $1.5 \mathrm{~m}$ from the tested system. The measurement of thermal radiation was made pointwise from the center of the sample surface and was performed with a frequency of $60 \mathrm{~s}$ for a period of $1 \mathrm{~h}$.

\subsubsection{Fire-Jet Test}

Two plates were subjected to a heating test similar to the fire-jet test: $0 \% \mathrm{MF}$ and $0.5 \% \mathrm{MF}$. The samples were chosen after the results of the thermal radiation investigation and the analysis of the results of the mechanical strengths, where the best results were achieved for the composite with the addition of $0.5 \%$ by weight of melamine fibers. The gas emitter was an oxygen-acetylene burner, which was set at a distance from the sample in such a way that the temperature on the surface did not exceed $1500{ }^{\circ} \mathrm{C}$ (Figure 4). 


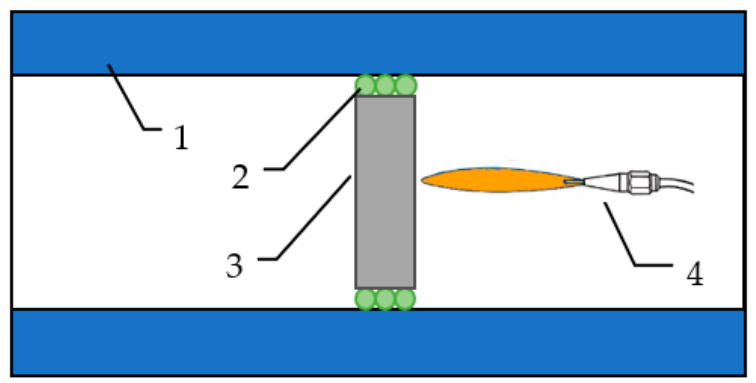

Figure 4. Scheme of the measuring system showing the mini fire-jet test: (1) thermal chamber; (2) high-temperature insulation material; (3) sample; (4) fire-jet system.

The test lasted until cracks were observed on the side of the plate, which was not exposed to the exposure of combustion gases or "open fire" (Figure 5).
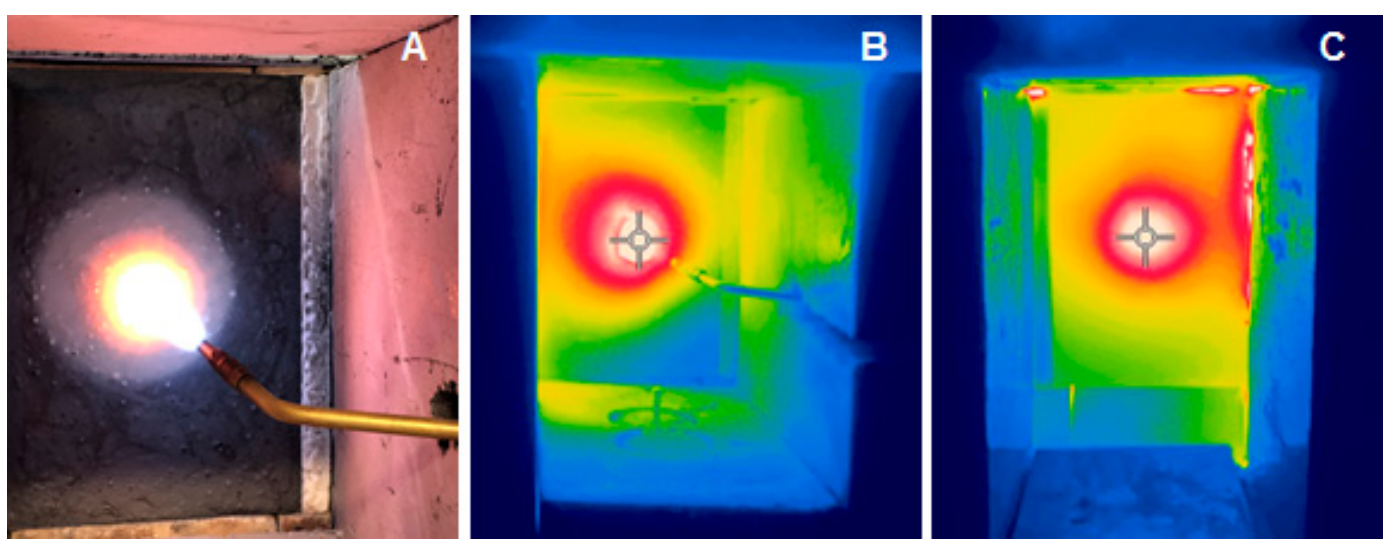

Figure 5. Mini fire-jet test example. (A,B) View from the side of the combusted gases; (C) view of the surface not thermally treated.

The temperature measurement on the side opposite to the heat source was made with a thermal imaging camera every $5 \mathrm{~min}$. The measurement was performed with a FLIR thermal imaging camera with a field of view (FOV) $\geq 38^{\circ}$, thermal sensitivity $<70 \mathrm{mK}$, measured infrared wavelength range in the range of 7-14 $\mu \mathrm{m}$ and pixel size $<15 \mu \mathrm{m}$. The use of this method guaranteed the continuity of the material surface and did not generate additional stresses.

\section{Results and Discussion}

\subsection{Density}

The results of the compressive and flexural strength tests are shown in Figure 6.

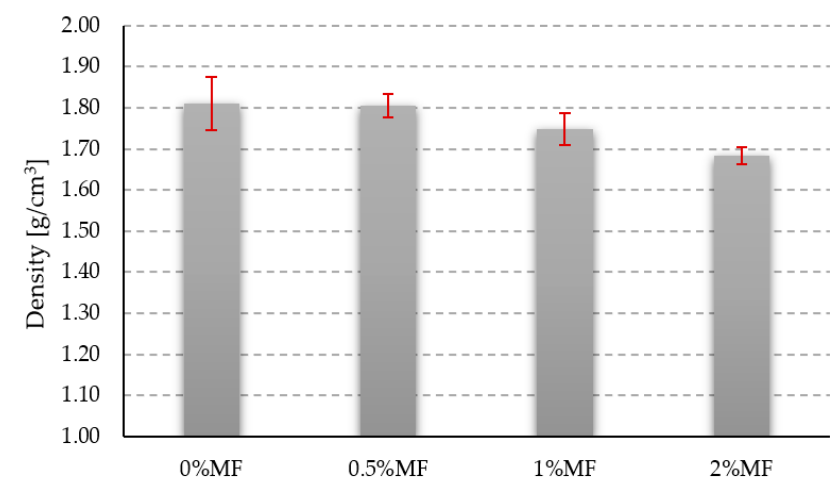

Figure 6. Density results of tested materials. 
Before carrying out the strength tests, in order to determine the density of the tested geopolymers, the samples intended for the compressive strength tests were measured and weighed. The obtained results of the geopolymer composites' density are shown in Figure 6. The density value for the material without reinforcement was $1.81 \mathrm{~g} / \mathrm{cm}^{3}$. In the case of the geopolymer composite with the addition of $0.5 \%$ by weight of melamine fibers, the density value was almost on the same level. The addition of the melamine reinforcement in the amount of $1 \%$ and $2 \%$ by weight allowed for a slight decrease in the density of composites in comparison to the reference sample, which were, respectively, $1.75 \mathrm{~g} / \mathrm{cm}^{3}$ and $1.68 \mathrm{~g} / \mathrm{cm}^{3}$. However, the decrease in these values is directly related to the lower density of the added melamine fibers equal to about $1.6 \mathrm{~g} / \mathrm{cm}^{3}$. The achieved results are in accordance with other research provided on geopolymer matrices reinforced by polymer fibers given in the literature $[25,29]$. The density of geopolymers is usually between $1.5 \mathrm{~g} / \mathrm{cm}^{3}$ and $2.0 \mathrm{~g} / \mathrm{cm}^{3}$ and is strictly related to the used raw materials such as fly ash. The addition of polymer fibers decreases the density of the composites because of their low weight.

\subsection{Strength Tests}

The results of the compressive and flexural strength tests for all investigated materials are shown in Figure 7. The results of both unreinforced and fiber-reinforced specimens are presented.

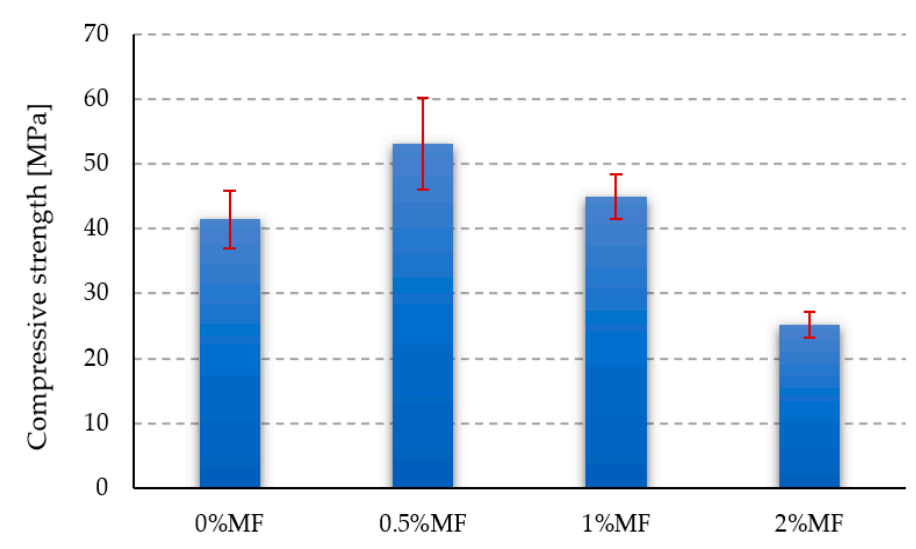

(a)

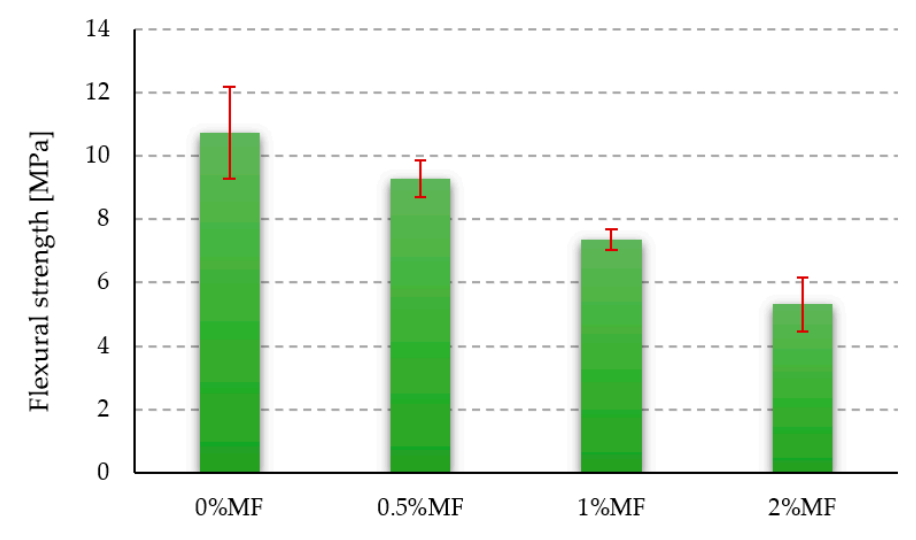

(b)

Figure 7. Compressive (a) and flexural (b) strength of tested materials.

The compressive strength for the samples made of the reference material (with pure geopolymer matrix) reached a value of about $41 \mathrm{MPa}$. Better results were obtained for geopolymer composites with the addition of $0.5 \%$ and $1 \%$ by weight of melamine fibers, for which the compressive strength was approximately $53 \mathrm{MPa}$ and $45 \mathrm{MPa}$, respectively 
(Figure 7a). In the case of the composite with the addition of $2 \%$ by weight of melamine, the determined compressive strength dropped significantly to a value of about $25 \mathrm{MPa}$, which is equal to about $60 \%$ of the compressive strength of the sample with the pure geopolymer matrix. It was most likely connected to high fiber content because by increasing their content in the composite, the workability of the geopolymer mass decreased significantly. In the case of the sample with the addition of $2 \%$ by weight of melamine reinforcement, the workability of the mass was the worst, and the obtained samples did not maintain the correct dimensions; the mass did not spread evenly, and the distribution of the fibers was most likely not homogeneous. The workability of the mass could also be influenced by the fact that the melamine fibers were characterized by high absorption of the activating solution. The highest compressive strength was obtained for the geopolymer composite with the addition of $0.5 \%$ by weight of melamine fibers, and its value was about $24 \%$ higher than the compressive strength value for samples made of a pure geopolymer matrix. This result seems to be promising for future applications and is coherent with the results of other research $[25,26,38-42]$.

During the analysis of the results obtained from the bending tests, it can be observed that the higher the melamine fiber content in the composite, the lower the obtained bending strength values. As a result, only samples made of the unreinforced geopolymer and samples with the addition of $0.5 \%$ by weight of melamine fibers were characterized by bending strength values above $9 \mathrm{MPa}$, amounting to $10.7 \mathrm{MPa}$ and $9.3 \mathrm{MPa}$, respectively (Figure $7 \mathrm{~b}$ ). The results show the nontypical behavior of the geopolymer composite reinforced by polymer fibers. The flexural strength usually increased [25], but an exception has been confirmed by other research teams. This behavior could be explained by a material imperfection that caused decreasing flexural strength or an improper interfacial mechanism between the fibers and the matrix [43-45].

\subsection{Thermal Radiation}

The graph in Figure 8 shows the temperature change of a geopolymer plate with different melamine contents measured on the outer surface of the plate as an insulating element (thermal barrier).

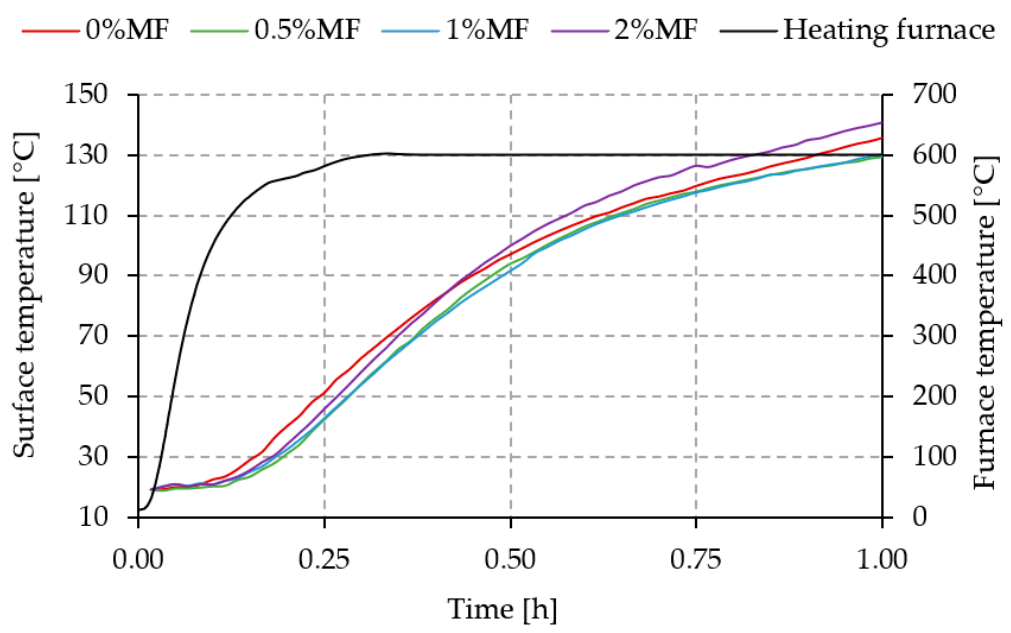

Figure 8. Temperature change depending on the heating time and the melamine content.

The green and blue curves corresponding to the composite containing $0.5 \%$ and $1 \%$ by weight of melamine in relation to the total weight of the geopolymer matrix do not show significant changes in the emission of thermal radiation with increasing temperature in the furnace. Compared to the geopolymer matrix without melamine addition, both curves are characterized by a lower temperature on average by about $4{ }^{\circ} \mathrm{C}$.

When comparing the pure geopolymer matrix (red curve) and the geopolymer matrix containing $2 \%$ by weight of melamine (purple curve), a lower temperature can be observed 
on the surface of the sample containing melamine in the initial heating stage. This situation changes after approximately $25 \mathrm{~min}$ of temperature rise in the furnace. After this time, the temperature measured on the outer surface of the plate shows a higher temperature by more than $4{ }^{\circ} \mathrm{C}$ compared to the pure geopolymer matrix.

A comparison of the temperature difference between the pure geopolymer matrix and the matrix with variable melamine content is shown in Figure 9.

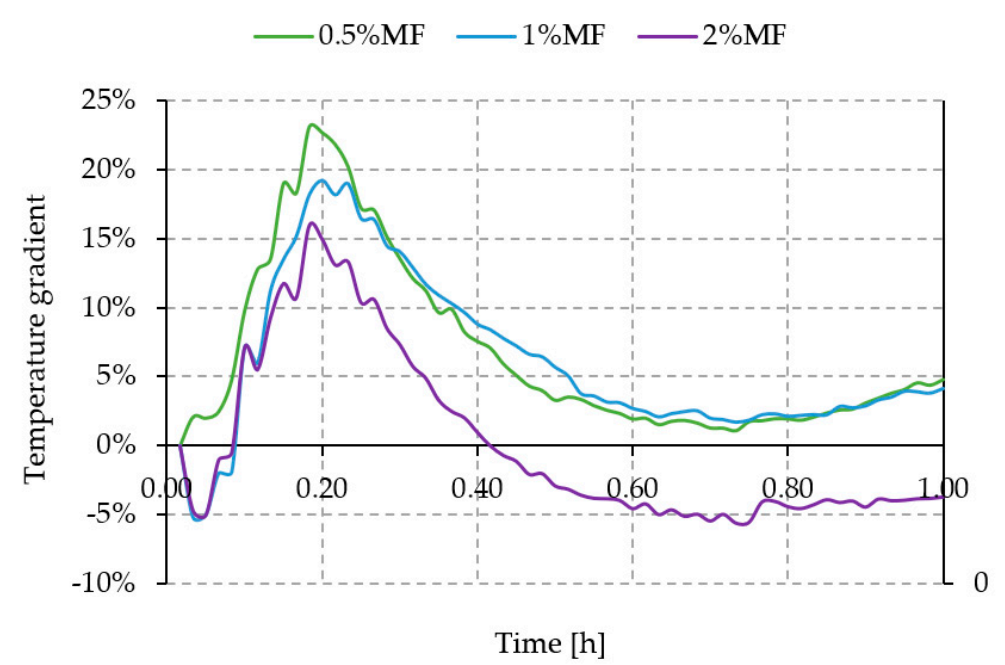

Figure 9. Temperature difference between the pure geopolymer matrix and the geopolymer matrix with variable melamine content.

Figure 10 shows exemplary photos of the sample surface before and after exposure to a temperature of $600{ }^{\circ} \mathrm{C}$. Discoloration and numerous surface cracks could be observed on the surface of the samples.

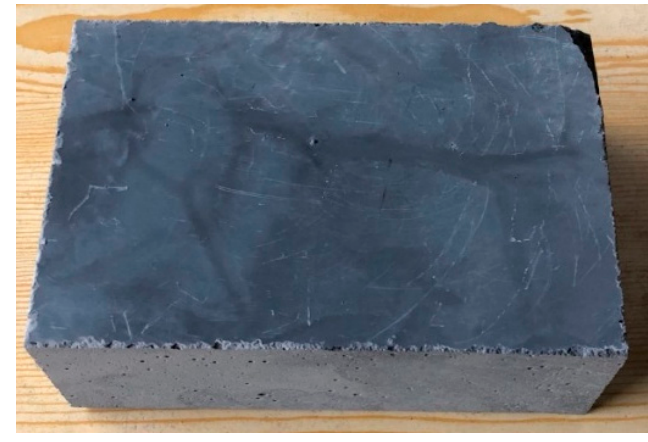

(a)

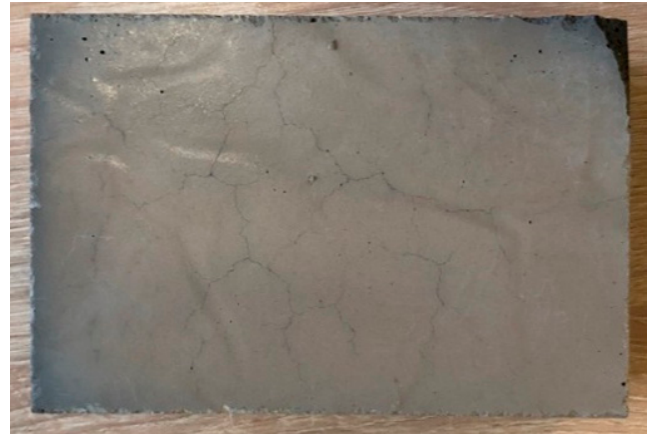

(b)

Figure 10. Exemplary photos of the sample surface before (a) and after (b) exposure to a temperature of $600{ }^{\circ} \mathrm{C}$.

\subsection{Fire-Jet Test}

Figure 11 presents the temperature changes measured on the outer surface of the plate (opposite to open fire) for geopolymer plates with different melamine contents. 


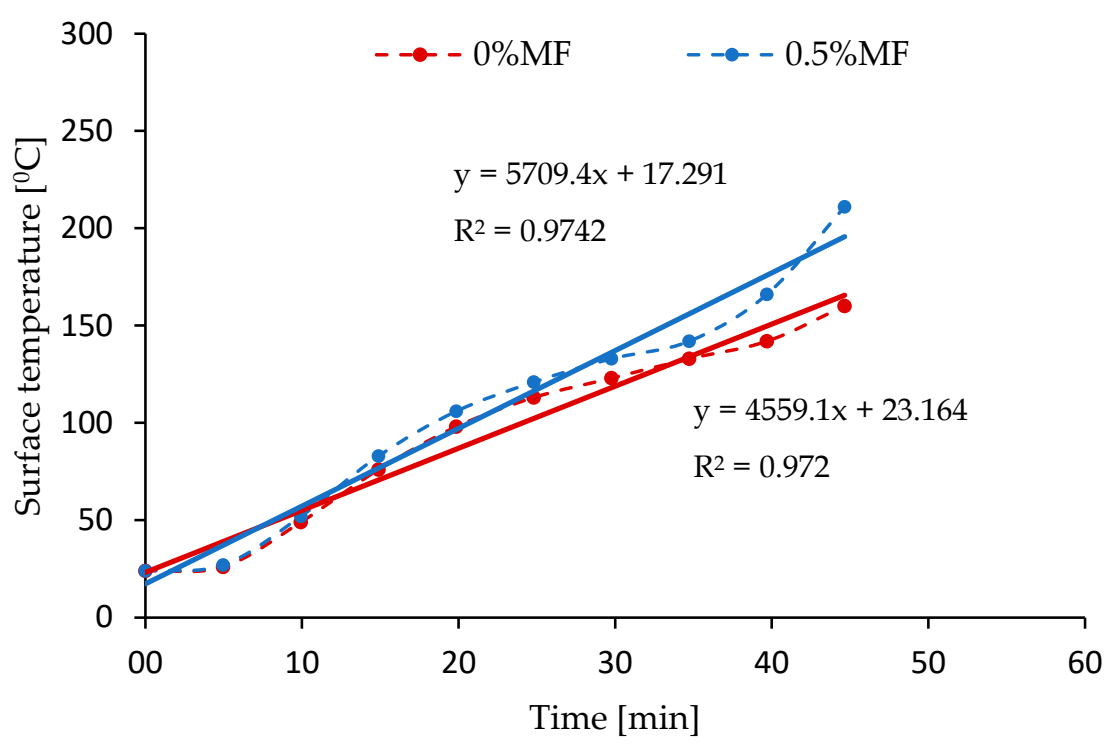

Figure 11. Temperature distribution on the surface of samples during the mini fire-jet test.

Analyzing the obtained curves shown in Figure 11, a higher temperature on the tested surface of the geopolymer plate with the addition of melamine fibers can be observed, which may be the result of a marked degradation of the surface after exposure to open fire. The visual observations after the test confirm that the sample with melamine was clearly degraded. It is clearly visible also as a temperature difference between the sample with melamine and the reference sample (with pure geopolymer matrix).

\section{Discussion}

This paper presents geopolymer composites reinforced with melamine fibers. The density measurement results are as expected showing that, with the addition of the melamine reinforcement, there is a slight decrease in the density of the composites. This is in line with other research conducted on polymeric fibers that have a density lower than the geopolymer matrix [25,29].

The compressive strength test results indicate that melamine fibers can be used as geopolymer reinforcement. The best result was achieved for a $0.5 \%$ by weight amount of reinforcement, approximately $53 \mathrm{MPa}$, compared to $41 \mathrm{MPa}$ for a pure matrix. The geopolymer composites with the addition of $1 \%$ and $2 \%$ by weight of melamine fibers displayed compressive strength values of approximately $45 \mathrm{MPa}$ and $25 \mathrm{MPa}$, respectively. The obtained results are in line with those of other research teams. In the literature, the reported compressive strength values for geopolymers based on fly ash are usually between 20 and $80 \mathrm{MPa}$ [25]. The obtained values are strongly dependent on fly ash quality [35,36]. The decrease in the compressive strength for the composite with $2 \%$ of fibers was caused by the worse workability of the geopolymer paste. This made the mixing process less efficient, which resulted in the formation of agglomerates of fibers in the material. Investigations conducted with the addition of other fibers confirmed that above a certain amount of the fiber, the mechanical properties of geopolymer composites decreases $[25,26,38]$. The overall tendency of increasing the compressive strength is not obvious, and much research shows that the compressive strength of geopolymer composites tends to decrease with an increasing amount of added polymer fibers [39-42].

However, the main reason for polymer fiber addition is not to increase the compressive strength but to improve the flexural strength and the behavior of the fracture tongues. It is expected that both of these properties will increase with the fiber amount [24,25]. The flexural strength provided in this research behaves quite differently. The best results were obtained for the samples made of an unreinforced geopolymer and samples with the addition of $0.5 \%$ by weight of melamine fibers, which were characterized by bending 
strength values above $9 \mathrm{MPa}$, amounting to $10.7 \mathrm{MPa}$ and $9.3 \mathrm{MPa}$, respectively. The obtained results are highly comparable with the range of values for geopolymers provided by other research teams. In the literature, the flexural strength values for geopolymers based on fly ash are usually reported between 3 and $10 \mathrm{MPa}$ [25]. The achieved results are strongly dependent on fly ash quality $[35,36]$. The overall tendency shows that flexural strength decreases with fiber addition. This behavior is not typical for polymeric fibers, and flexural strength typically increases by about $50 \%$ [25]. However, some studies demonstrate that it decreases or does not significantly change. Authors usually explain this by voids in the material, fiber agglomeration or the improper interfacial mechanism between the fibers and the matrix [43-45].

The thermal radiation measurements and fire-jet test do not confirm the increasing thermal and fire resistance of the composites reinforced by melamine fiber. The literature shows geopolymers with the addition of various fibers can be excellent materials for thermaland fire-resistant applications $[19,46]$. The obtained results of the fire-jet test could be compared with the sandwich panels investigated by a team from the Czech Republic [18,47], where a geopolymer was applied as one of the layers. These composites resisted flames for more than $13 \mathrm{~min}[18,47]$. However, the samples with melamine fibers degraded significantly faster than those without reinforcement during the fire test. This may be due to the lack of additional surface coverage and the action of melamine fibers, which have a much lower melting point than the matrix material ("hot spots").

\section{Conclusions}

This paper presents geopolymer composites reinforced with melamine fibers. The results indicate that the inclusion of $0.5 \%$ by weight of melamine fibers significantly enhanced compressive strength and slightly decreased flexural strength in comparison to the unreinforced geopolymer based on fly ash, which means that melamine fibers can be successfully used to increase resistance to the axial compression of geopolymer composites. The obtained results seem to be promising for future applications, showing that it is possible to produce composites of reasonable properties from industrial wastes (fly ash) and melamine fibers. It should be noted that when melamine fibers are used as reinforcement for geopolymer composites, their amount should not exceed $0.5 \%$ by weight as exceeding this value may result in the deterioration of the workability of the geopolymer's mass and a significant reduction in compressive strength and bending strength.

The obtained differences of the outer surface temperature of the tested plates at $4{ }^{\circ} \mathrm{C}$ in favor of composites with the addition of $0.5 \%$ and $1 \%$ of melamine fibers in relation to unreinforced geopolymer seem to be small, and further research should be carried out in order to achieve temperature stabilization (steady state) on the outer surface of the tested plate.

Practical applications require further testing to optimize the mechanical properties of the composites as well as investigating other properties such as water absorption and resistance in various environments.

Author Contributions: Conceptualization, B.K., P.B. and D.M.; methodology, B.K., P.B. and D.M.; formal analysis, B.K., P.B. and D.M.; investigation, B.K., P.B. and D.M.; resources, K.K.; writingoriginal draft preparation, B.K.; writing-review and editing, P.B., D.M. and K.K.; supervision, K.K.; funding acquisition, K.K. All authors have read and agreed to the published version of the manuscript.

Funding: The presented works were carried out as part of the project: "Geopolymer foams with low thermal conductivity produced on the basis of industrial waste as an innovative material for the circular economy", which is financed by the National Center for Research and Development under the LIDER X program. Grant No.: LIDER/31/0168/L-10/18/NCBR/2019.

Institutional Review Board Statement: Not applicable.

Informed Consent Statement: Not applicable. 
Data Availability Statement: Institute of Materials Engineering, Faculty of Material Engineering and Physics, Cracow University of Technology, Jana Pawła II 37, 31-864 Cracow, Poland.

Conflicts of Interest: The authors declare no conflict of interest.

\section{References}

1. Pacheco-Torgal, F.; Castro-Gomes, J.; Jalali, S. Alkali-activated binders: A review Part 1. Historical background, terminology, reaction mechanisms and hydration products. Constr. Build. Mater. 2008, 22, 1305-1314. [CrossRef]

2. Davidovits, J. Geopolymers: Ceramic-Like Inorganic Polymers. J. Ceram. Sci. Technol. 2017, 3, 335-350.

3. Provis, J.L.; Van Deventer, J.S.J. Geopolymers: Structure, Processing, Properties and Industrial Applications; Woodhead Publishing Limited: Cambridge, UK, 2009.

4. Luukkonen, T.; Sarkkinen, M.; Kemppainen, K.; Rämö, J.; Lassi, U. Metakaolin geopolymer characterization and application for ammonium removal from model solutions and landfill leach-ate. Appl. Clay Sci. 2016, 119, 266-276. [CrossRef]

5. Wang, H.; Li, H.; Yan, F. Synthesis and mechanical properties of metakaolinite-based geopolymer. Colloids Surf. A Physicochem. Eng. Asp. 2005, 268, 1-6. [CrossRef]

6. Duxson, P.; Mallicoat, S.W.; Lukey, G.C.; Kriven, W.M.; Van Deventer, J.S.J. The effect of alkali and Si/Al ratio on the development of mechanical properties of metakaolin-based geopolymers. Colloids Surf. A Physicochem. Eng. Asp. 2007, 292, 8-20. [CrossRef]

7. Sitarz, M.; Hager, I.; Choińska, M. Evolution of mechanical properties with time of fly-ash-based geopolymer mortars under the effect of granulated ground blast furnace slag addition. Energies 2020, 13, 1135. [CrossRef]

8. Zhang, Z.; Provis, J.L.; Reid, A.; Wang, H. Geopolymer foam concrete: An emerging material for sustainable construction. Constr. Build. Mater. 2014, 56, 113-127. [CrossRef]

9. Bumanis, G.; Vitola, L.; Pundiene, I.; Sinka, M.; Bajare, D. Gypsum, Geopolymers, and starch-Alternative binders for bio-based building materials: A review and life-cycle assessment. Sustainability 2020, 12, 5666. [CrossRef]

10. Assi, L.N.; Ghahari, S.A.; Deaver, E.; Leaphart, D.; Ziehl, P. Improvement of the early and final compressive strength of fly ash-based geopolymer concrete at ambient conditions. Constr. Build. Mater. 2016, 123, 806-813. [CrossRef]

11. Cheng, T.W.; Chiu, J.P. Fire-resistant geopolymer produce by granulated blast furnace slag. Miner. Eng. 2003, 16, 205-210. [CrossRef]

12. Nguyen, H.; Carvelli, V.; Adesanya, E.; Kinnunen, P.; Illikainen, M. High performance cementitious composite from alkaliactivated ladle slag reinforced with polypropylene fibers. Cem. Concr. Compos. 2018, 90, 150-160. [CrossRef]

13. Cioffi, R.; Maffucci, L.; Santoro, L. Optimization of geopolymer synthesis by calcinations and polycondensation of a kaolinitic residue resources. Conserv. Recycl. 2003, 40, 27-38. [CrossRef]

14. Nyale, S.M.; Babajide, O.O.; Birch, G.D.; Böke, N.; Petrik, L.F. Synthesis and characterization of coal fly ash-based foamed geopolymer. Procedia Environ. Sci. 2013, 18, 722-730. [CrossRef]

15. Böke, N.; Birch, G.D.; Nyale, S.M.; Petrik, L.F. New synthesis method for the production of coal fly ash-based foamed geopolymers. Constr Build. Mater. 2015, 75, 189-199. [CrossRef]

16. Łach, M.; Korniejenko, K.; Mikuła, J. Thermal Insulation and Thermally Resistant Materials Made of Geopolymer Foams. Procedia Eng. 2016, 151, 410-416. [CrossRef]

17. Shill, K.S.; Al-Deen, S.; Ashraf, M.; Hutchison, W. Resistance of fly ash based geopolymer mortar to both chemicals and high thermal cycles simultaneously. Constr. Build. Mater. 2020, 239, 117886. [CrossRef]

18. Hýsek, Š.; Frydrych, M.; Herclík, M.; Louda, P.; Fridrichová, L.; Le Van, S.; Le Chi, H. Fire-Resistant Sandwich-Structured Composite Material Based on Alternative Materials and Its Physical and Mechanical Properties. Materials 2019, $12,1432$. [CrossRef]

19. Le, V.S.; Louda, P.; Tran, H.N.; Nguyen, P.D.; Bakalova, T.; Ewa Buczkowska, K.; Dufkova, I. Study on Temperature-Dependent Properties and Fire Resistance of Metakaolin-Based Geopolymer Foams. Polymers 2020, 12, 2994. [CrossRef]

20. Mikuła, J.; Łach, M. Geopolymers-A new environment friendly alternative to concrete based on portland cement. Part 1Introduction. In Pro-Ecological Solutions in the Field of Production. Modern Environmentally Friendly Composite Materials; Mikuła, J., Ed.; Cracow University of Technology: Cracow, Poland, 2007; Volume 1, pp. 13-179.

21. Mehta, A.; Siddique, R. Sulfuric acid resistance of fly ash based geopolymer concrete. Constr. Build. Mater. 2017, 146, 136-143. [CrossRef]

22. Sotelo-Pina, C.; Aguilera-Gonzalez, E.N.; Martinez-Luevanos, A. Geopolymers: Past, Present and Future of Low Carbon Footprint Eco-materials. In Handbook of Ecomaterials; Martinez, L.M.T., Kharissowa, O.V., Kharisov, B., Eds.; Springer: Cham, Switzerland, 2019; pp. 2765-2785.

23. Korniejenko, K.; Frączek, E.; Pytlak, E.; Adamski, M. Mechanical properties of geopolymer composites reinforced with natural fibers. Procedia Eng. 2016, 151, 388-393. [CrossRef]

24. Ranjbar, N.; Zhang, M. Fiber-Reinforced geopolymer composites: A review. Cem. Concr. Compos. 2020, 107, 103498. [CrossRef]

25. Korniejenko, K.; Lin, W.-T.; Šimonová, H. Mechanical Properties of Short Polymer Fiber-Reinforced Geopolymer Composites. J. Compos. Sci. 2020, 4, 128. [CrossRef]

26. Silva, F.J.; Thaumaturgo, C. Fibre reinforcement and fracture response in geopolymeric mortars. Fatigue Fract. Eng. Mater. Struct. 2003, 26, 167-172. [CrossRef] 
27. Nawaz, M.; Heitor, A.; Sivakumar, M. Geopolymers in construction-Recent developments. Constr. Build. Mater. $2020,260,120472$. [CrossRef]

28. Ghahari, S.; Assi, L.N.; Alsalman, A.; Alyamaç, K.E. Fracture Properties Evaluation of Cellulose Nanocrystals Cement Paste. Materials 2020, 13, 2507. [CrossRef]

29. Bazan, P.; Kozub, B.; Łach, M.; Korniejenko, K. Evaluation of Hybrid Melamine and Steel Fiber Reinforced Geopolymers Composites. Materials 2020, 13, 5548. [CrossRef]

30. Tang, W.; Cao, Y.; Qian, L.; Chen, Y.; Qiu, Y.; Xu, B.; Xin, F. Synergistic Charring Flame-Retardant Behavior of Polyimide and Melamine Polyphosphate in Glass Fiber-Reinforced Polyamide 66. Polymers 2019, 11, 1851. [CrossRef]

31. Diniz, A.T.S.; Huth, C.; Schartel, B. Dripping and decomposition under fire: Melamine cyanurate vs. glass fibres in polyamide 6. Polym. Degrad. Stab. 2020, 171, 109048. [CrossRef]

32. Levinta, N.; Corobea, M.C.; Vuluga, Z.; Nicolae, C.-A.; Gabor, A.R.; Raditoiu, V.; Osiac, M.; Teodorescu, G.-M.; Teodorescu, M. Bio-Based Polyamide 1010 with a Halogen-Free Flame Retardant Based on Melamine-Gallic Acid Complex. Polymers 2020, 12, 1482. [CrossRef]

33. Azimi, E.A.; Al Bakri Abdullah, M.M.; Yun Ming, L.; Heah, C.Y.; Hussin, K.; Aziz, I.H. Review of Geopolymer Materials for Thermal Insulating Applications. Key Eng. 2015, 660, 17-22. [CrossRef]

34. Łach, M.; Mierzwiński, D.; Korniejenko, K.; Mikuła, J. Geopolymer foam as a passive fire protection. MATEC Web Conf. 2018, 247, 00031. [CrossRef]

35. Korniejenko, K.; Halyag, N.P.; Mucsi, G. Fly Ash as a Raw Material for Geopolymerisation—Chemical Composition and Physical Properties. IOP Conf. Ser. Mater. Sci. Eng. 2019, 706, 012002.

36. Korniejenko, K.; Łach, M.; Marczyk, J.; Ziejewska, C.; Halyag, N.P.; Mucsi, G. Fly Ash as a Raw Material for GeopolymerisationMineralogical Composition and Morphology. IOP Conf. Ser. Mater. Sci. Eng. 2019, 706, 012006. [CrossRef]

37. Maity, S.; Singha, K. Melamine fiber-Synthesis, features and applications. Chem. Fibers Int. 2012, 62, $183-186$.

38. Dias, D.P.; Thaumaturgo, C. Fracture toughness of geopolymeric concretes reinforced with basalt fibers. Cement and Concrete Composites. Cem. Concr. Compos. 2005, 27, 49-54. [CrossRef]

39. Shaikh, F.U.A. Tensile and flexural behaviour of recycled polyethylene terephthalate (PET) fibre reinforced geopolymer composites. Constr. Build. Mater. 2020, 245, 118438. [CrossRef]

40. Chindaprasirt, P.; Rattanasak, U. Synthesis of polypropylene fiber/high-calcium fly ash geopolymer with outdoor heat exposure. Clean Technol. Environ. 2017, 19, 1985-1992. [CrossRef]

41. Noushini, A.; Castel, A.; Gilbert, R.I. Creep and shrinkage of synthetic fibre-reinforced geopolymer concrete. Mag. Concr. Res. 2019, 71, 1070-1082. [CrossRef]

42. Baykara, H.; Cornejo, M.H.; Espinoza, A.; García, E.; Ulloa, N. Preparation, characterization, and evaluation of compressive strength of polypropylene fiber reinforced geopolymer mortars. Heliyon 2020, 6, e03755. [CrossRef]

43. Yuan, Y.; Zhao, R.; Li, R.; Wang, Y.; Cheng, Z.; Li, F.; Ma, Z.J. Frost resistance of fiber-reinforced blended slag and Class F fly ashbased geopolymer concrete under the coupling effect of freeze-thaw cycling and axial compressive loading. Constr. Build. Mater. 2020, 250, 118831. [CrossRef]

44. Rashad, A.M. The effect of polypropylene, polyvinyl-alcohol, carbon and glass fibres on geopolymers properties. Mater. Sci. Technol. 2019, 35, 127-146. [CrossRef]

45. Bhutta, A.; Farooq, M.; Zanotti, C.; Banthia, N. Pull-out behavior of different fibers in geopolymer mortars: Effects of alkaline solution concentration and curing. Mater. Struct. 2017, 50, 80. [CrossRef]

46. Silva, G.; Salirrosas, J.; Ruiz, G.; Kim, S.; Nakamatsu, J.; Aguilar, R. Evaluation of fire, high-temperature and water erosion resistance of fiber-reinforced lightweight pozzolana-based geopolymer mortars. IOP Conf. Ser. Mater. Sci. Eng. 2019, 706, 012016. [CrossRef]

47. Le Van, S.; Hájková, P.; Kovacic, V.; Bakalova, T.; Lukáš, V.; Le Chi, H.; Ceccon Seifert, K.; Pereira Peres, A.; Louda, P. Thermal Conductivity of Reinforced Geopolymer Foams. Ceram.-Silikáty 2019, 63, 365-373. 